\title{
NASI AUTORZY
}

BUCHWALD-PELCOWA PAULINA - emerytowany prof. zw. dr hab., Biblioteka Narodowa, Warszawa biblioteka.wdib@uw.edu.pl

CHAMERA-NOWAK AGNIESZKA, dr, Katedra Książki i Historii Mediów, Uniwersytet Warszawski achamera@uw.edu.pl

DASZKIEWICZ PIOTR, dr hab. prof. Polskiej Akademii Nauk, Muséum National d'Histoire Naturelle, Paryż; Instytut Historii Nauki Polskiej Akademii Nauk, Warszawa piotrdas@mnhn.fr

DOMŻAŁ ZBIGNIEW - prof. nadzw. dr hab., Uczelnia Nauk Społecznych, Łódź kanclerz@wsez.pl

DZIADEK JUSTYNA - mgr, Instytut Historii, Uniwersytet Jana Kochanowskiego w Kielcach wami16@interia.pl

EDEL PHILIPPE - Cercle d'Histoire Alsace-Lituanie Strasbourg edel-matuolis@wanadoo.fr

FIGASZEWSKA KAROLINA - lic., Katedra Książki i Historii Mediów, Uniwersytet Warszawski karolina.figaszewska@gmail.com

FRANCZYK-CEGŁA AGNIESZKA - dr, Dział Starych Druków, Zakład Narodowy im. Ossolińskich, Wrocław agnieszka.franczyk-cegla@znio.pl

FURRER NORBERT, dr, Historisches Institut, Universität Bern n.furrer@bluewin.ch 
GĘBOŁYŚ ZDZISŁAW - prof. nadzw. dr hab., Katedra Informacji Naukowej i Bibliologii, Uniwersytet Kazimierza Wielkiego w Bydgoszczy zdzislaw.gebolys@ukw.edu.pl

JAROSZ DARIUSZ - prof. zw. dr hab., Instytut Historii Polskiej Akademii Nauk, Warszawa darjarosz@wp.pl

JUDA MARIA - prof. zw. dr hab., Instytut Informacji Naukowej i Bibliotekoznawstwa, Uniwersytet Marii Curie-Skłodowskiej w Lublinie dyrekt@biblio.umcs.lublin.pl

KALCZYŃSKA MARIA - prof. nadzw. dr hab., Wydział Ekonomii i Zarządzania, Politechnika Opolska maria.wilno@gmail.com

KAMLER ANNA - prof. nadzw. dr hab., Katedra Książki i Historii Mediów, Uniwersytet Warszawski akamler@uw.edu.pl

KOSMAN JANINA - dr, Archiwum Państwowe w Szczecinie j.kosman@szczecin.ap.gov.pl

KOTOWSKI ROBERT - dr hab., Katedra Badań nad Bibliotekami i Innymi Instytucjami Kultury, Uniwersytet Warszawski; Muzeum Narodowe w Kielcach r.kotowski@uw.edu.pl; r.kotowski@mnki.pl

LEWANDOWICZ-NOSAL GRAŻYNA - dr, Instytut Książki i Czytelnictwa, Biblioteka Narodowa, Warszawa g.lewandowicz@bn.org.pl

ŁAKOMY AGNIESZKA - dr, Instytut Bibliotekoznawstwa i Informacji Naukowej, Uniwersytet Śląski w Katowicach

a.lakomy@interia.pl

ŁUSZPAK AGNIESZKA - dr, Instytut Informacji Naukowej i Bibliotekoznawstwa, Uniwersytet Wrocławski agnieszka.luszpak@uwr.edu.pl 
MARUSZAK ELŻBIETA - mgr, Biblioteka Wydziału Dziennikarstwa, Informacji i Bibliologii, Uniwersytet Warszawski

e.szklarska-maruszak@uw.edu.pl

MILEWSKA-KOZŁOWSKA JOANNA - dr, Gabinet Starych Druków, Biblioteka Uniwersytecka w Warszawie j.milewska-kozlowska@uw.edu.pl

NOWICKI RYSZARD - prof. nadzw. dr hab., Katedra Informacji Naukowej i Bibliologii, Uniwersytet Kazimierza Wielkiego w Bydgoszczy nowickiryszard@interia.pl

PIDŁYPCZAK-MAJEROWICZ MARIA - emerytowany prof. nadzw. dr hab., Uniwersytet Pedagogiczny im. Komisji Edukacji Narodowej w Krakowie m.pidlypczak@gmail.pl

PIETRZKIEWICZ DOROTA - mgr, Katedra Książki i Historii Mediów, Uniwersytet Warszawski d.pietrzkiewicz@uw.edu.pl

POTKOWSKI EDWARD - emerytowany prof. zw. dr hab., Uniwersytet Warszawski potkowski@uw.edu.pl

PRZYBYŁ-SADOWSKA ELŻBIETA - dr hab., Instytut Religioznawstwa, Uniwersytet Jagielloński eprzybyl@iphils.uj.edu.pl

ROMULEWICZ ANITA - mgr, Dział Informacyjno-Bibliograficzny Wojewódzkiej Biblioteki Publicznej w Olsztynie arom2001@poczta.onet.pl

SEROKA KATARZYNA, dr, Katedra Książki i Historii Mediów, Uniwersytet Warszawski kseroka@uw.edu.pl

SKUMANOV SARAH, mgr, Katedra Książki i Historii Mediów, Uniwersytet Warszawski s.skumanov@student.uw.edu.pl 
SOBOL-KIEŁBANIA MAŁGORZATA - mgr, Miejska Biblioteka Publiczna im. J. Słowackiego w Tarnowie margaret.sobol@gmail.com

TADEUSIEWICZ HANNA - prof. zw. dr hab., Katedra Informatologii i Bibliologii, Uniwersytet Łódzki kbin@uni.lodz.pl

WAŁKÓWSKI ANDRZEJ - prof. zw. dr hab., Katedra Informatologii i Bibliologii, Uniwersytet Łódzki andrzej.walkowski@uni.lodz.pl

WYSOCKA JUSTYNA - mgr, Katedra Edytorstwa i Nauk Pomocniczych, Uniwersytet Jagielloński justyna.wysocka@doctoral.uj.edu.pl 

